\title{
Positive and Negative Religious Coping in German Breast Cancer Patients
}

\author{
Christian Zwingmann, ${ }^{1,4}$ Markus Wirtz, ${ }^{2}$ Claudia Müller, ${ }^{1}$ \\ Jürgen Körber, ${ }^{3}$ and Sebastian Murken ${ }^{1}$
}

Accepted for publication: July 27, 2006

Published online: September 2, 2006

\begin{abstract}
A growing interest has been focusing on the relationship between religious coping and psychosocial adjustment among cancer patients. However, previous research mostly has not differentiated between positive and negative components of religious coping. The current cross-sectional study investigated the role of both positive religious coping, i.e., a confident and constructive turning to religion, and negative religious coping, i.e., religious struggle and doubt, in a sample of 156 German breast cancer patients. Participants were assessed upon admission to an inpatient rehabilitation program. In addition to religious coping, two basic nonreligious coping styles (depressive coping and active problem-focused coping) and psychosocial adjustment (anxiety and depression) were measured. Major research questions concerning the mediating role of nonreligious coping and the relative predictive power of positive and negative religious coping were primarily addressed using structural equation modeling. Results indicated that the relationship between religious coping and psychosocial outcomes was completely mediated by nonreligious coping, whereby only depressive coping and not active problem-focused coping proved to be a mediating variable. Positive and negative religious coping were somewhat positively related to each other; their (indirect) predictive power on psychosocial adjustment was identical though in an opposite direction. All in all, the results correspond to previous Anglo-American research. There are, however, some discrepancies which may be due to the specific religious-cultural background in Germany.
\end{abstract}

KEY WORDS: positive and negative religious coping; breast cancer; Germany; structural equation modeling.

\section{INTRODUCTION}

Within the last few years the connection between religiousness and psychosocial adjustment has become a subject of increasing interest within the field of health care (Koenig et al., 2001; Plante and Sherman, 2001). Religious or-somewhat more

\footnotetext{
${ }^{1}$ Psychology of Religion Research Group, University of Trier, Bad Kreuznach, Germany.

${ }^{2}$ Department of Rehabilitation Psychology, University of Freiburg, Freiburg, Germany.

${ }^{3}$ Rehabilitation Center Nahetal, Bad Kreuznach, Germany.

${ }^{4}$ To whom correspondence should be addressed at Psychology of Religion Research Group, University of Trier, FranziskaPuricelli-Str. 3, D-55543 Bad Kreuznach, Germany; e-mail: christian.zwingmann@web.de.
}

broadly defined-spiritual issues seem to play an important role in the coping process for many patients, particularly those facing severe and potentially lifethreatening illness such as cancer (Gall et al., 2005; MacLean et al., 2003). Across studies of participants with diverse types of cancer the majority reported, often spontaneously, religious faith to be a major source of support in dealing with their illness (Feher and Maly, 1999; Flannelly et al., 2002). It was assumed that religious involvement may help cancer patients in order to relieve stress, retain a sense of control, maintain hope and self-esteem as well as a sense of meaning and purpose in life, and to facilitate social support from a religious community (e.g., Coward, 1995; Levin, 1996; Moadel et al., 1999; Taylor, 1995). 
However, quantitative studies involving cancer patients and investigating religiousness as a global dispositional variable have yielded mixed results (Pargament et al., 2005; Stefanek et al., 2005). On the one hand, several results indicated religious involvement to be modestly but meaningfully associated with psychosocial adjustment, various dimensions of health-related quality of life, and beneficial coping strategies (e.g., Baider et al., 1999; Brady et al., 1999; Gall, 2000; Gioiella et al., 1998; Mehnert et al., 2003; Schnoll et al., 2000). On the other hand, null findings and even negative associations were also shown, at least for some of the target variables (e.g., Cotton et al., 1999; Holland et al., 1999; Rifkin et al., 1999; Silberfarb et al., 1991; Tate and Forchheimer, 2002). Thus, firm conclusions cannot yet be drawn (Stefanek et al., 2005).

Stronger and more clear-cut relationships might be found, when assessing religious coping strategies in place of global dispositional religious variables: Whereas dispositional religiousness denotes religious involvement in general, religious coping sets the focus on the way in which patients specifically draw on religion in a situation of crisis (Pargament, 1997; Sherman and Simonton, 2001). Thus, an exploration of religious coping provides information about functional religious aspects which may be more or less distinct from dispositional religiousness. In samples other than cancer patients several studies have already examined specific types of religious coping (see Pargament, 1997, for an overview). In these studies adjustment to difficult circumstances appeared to be better predicted by religious coping than by general religious orientation (e.g., Pargament et al., 1990). Moreover, religious coping strategies showed differential relationships to the outcomes of various stressful situations (see Pargament, 1997; Zwingmann and Murken, 2000, for an overview). More specifically, religious coping was helpful or harmful depending on the particular type of religious coping strategy employed. Thus, religious coping would appear to be an ambivalent phenomenon which does not automatically entail beneficial outcomes.

Higher order factor analyses have revealed that particular religious coping methods can be classified into two broad overarching patterns: positive and negative religious coping (Pargament et al., 1998). In general, positive religious coping strategies, those which reflect a confident and constructive turning to religion for support, tend to be beneficial for people undergoing stressful life events (Ano and Vasconcelles, 2005; Koenig et al., 2001). In contrast, negative religious coping strategies, those which reflect an engaging in religious struggle and doubt, are generally more maladaptive (Ano and Vasconcelles, 2005; Exline and Rose, 2005). The Brief RCOPE developed by Pargament et al. $(1998,2000)$ can be considered a well-established measure of positive and negative religious coping (Sherman and Simonton, 2001).

Returning to cancer patients, some studies have indeed also examined the impact of religious coping strategies (e.g., Alferi et al., 1999; Carver et al., 1993; Nairn and Merluzzi, 2003; Sherman et al., 2000). In psycho-oncological research these investigations have helped shift the focus from patients' dispositional religiousness to their specific responses to illness. However, only few items or a single scale were used and predominantly positive aspects of religious coping were measured (Thuné-Boyle et al., 2006). Hence, only limited information concerning the various correlates of religious coping was provided, with religious struggle and doubt in particular having received little attention. Only recently, Sherman et al. (2005) investigated positive and negative religious coping in a sample of multiple myeloma patients facing bone marrow transplantation. Results indicated that after controlling for potential demographic and medical confounders, only negative religious coping was significantly related to various psychosocial outcome measures. For cancer care and research, this finding underscores the need to distinguish between different patterns of religious coping and points to the importance of a potentially negative influence of religious struggle and doubt on the adaptation process.

Beyond the distinction of positive and negative religious coping, there is some obscurity about the question as to whether religious coping contributes to psychosocial adjustment directly and uniquely or rather through other pathways, such as by stimulating nonreligious coping strategies (Siegel et al., 2001). As Pargament et al. (1990) put it, religious coping may be predictive of psychosocial adjustment but functionally equivalent to traditional nonreligious coping measures. If this were the case there would be no general need to identify religious coping variables as specific predictors of outcomes. However, in their cross-sectional study of members of Christian churches who envisioned serious negative life events, Pargament et al. (1990) showed that religious coping variables predicted outcomes beyond the effects of nonreligious coping strategies. Similarly, a recent cross-sectional study conducted by Burker et al. 
(2005) in a sample of lung transplant candidates concluded that religious and nonreligious coping were not functionally redundant but independent components of psychosocial functioning. Moreover, Tix and Frazier (1998) found that after controlling for measures of cognitive restructuring, internal control, and social support religious coping predicted life satisfaction 12 months after transplantation. These and other findings (see Pargament, 1997, for an overview) suggest that religious coping represents a distinctive resource, one that cannot be "explained away" in terms of presumably more basic phenomena (Pargament, 2002).

Research with cancer patients to date has seldom examined the question of unique contributions of religious variables to psychosocial outcomes, and in doing so, has predominantly focused on dispositional religiousness or spirituality: A crosssectional study by Gall (2000) found that religious variables, but not nonreligious resources predicted emotional well-being in long-term breast cancer survivors. However, in a sample of patients with various types of cancer, self-efficacy proved-at least partially - to be a mediating variable between a positive religious coping style and adjustment (Nairn and Merluzzi, 2003). Yet another pattern was reported by Holland et al. (1999). In participants with malignant melanoma religious/spiritual predictors were unrelated to psychosocial adjustment but substantially associated with an active-cognitive coping style. Whereas this correlational finding was replicated in a recent German study (Mehnert et al., 2003), a similar investigation in an Israeli sample found religious predictors related to both psychosocial adjustment and active-cognitive coping (Baider et al., 1999). All in all, the picture is decidedly mixed. The potential mediating role of nonreligious coping within the religion-health relationship should be more directly addressed within cancer research.

A final point must be emphasized: So far, psycho-oncological research of religiousness or spirituality has been predominantly conducted in the United States. Thus, findings are limited to this specific religious-cultural context and should be augmented by contributions from other countries. For example, only little evidence is available from Germany (Zwingmann, 2005b) although there are considerable religious-cultural differences to the United States: Whereas belief in God is very widespread among Americans ( $>96 \%$ ) and almost constant since 1944 (Bishop, 1999), it is remarkably declining in Germany, presently totaling $63 \%$ in the former West German states and merely 13\% in the new East German states (Terwey, 2003). Concomitantly, there is an ongoing crisis of religious institutions in Germany bringing about the phenomenon of "believing without belonging." That is to say, religious beliefs are becoming increasingly personal, detached, and heterogeneous (Jagodzinski and Dobbelaere, 1995). Against this background, religious coping may well be a less frequent or less influential response to life-threatening illness in Germany (Frick et al., 2006; Zwingmann, 2005a).

Positive and negative religious coping patterns have not yet been differentially investigated in German cancer patients. However, in accordance with the international literature, some German studies also suggest that cancer patients view religiousness as important in dealing with their illness (Muthny et al., 1992). Furthermore, benevolent religious and spiritual attitudes basically tend to be favorable in coping with cancer (Filipp et al., 1990; Ferring et al., 1994; Mehnert et al., 2003) and seem to constitute specific psychosocial needs (Büssing et al., 2005; Frick et al., 2006).

The purpose in conducting the present investigation was to study the role of positive and negative religious coping in a sample of German breast cancer patients. According to our introductory remarks, three specific research questions were addressed:

1. Do patients with certain demographic and cancer-related characteristics prefer a particular religious coping pattern?

2. Do positive and negative religious coping contribute to psychosocial adjustment uniquely or indirectly by affecting nonreligious coping strategies?

3. Are positive and negative religious coping patterns equally predictive of psychosocial adjustment?

\section{METHODS}

\section{Procedure and Patients}

This was a cross-sectional study with 156 German breast cancer patients participating. Patients completed questionnaires at admission to an inpatient rehabilitation program. Patients were eligible for participation in the study if they had been newly diagnosed and were fluent in German. In excluding patients with recurrent breast cancer, we attempted 
to achieve a relatively homogeneous sample with regard to course of disease and treatment.

The study was reviewed and approved by the Ethic Committee of the "Landesärztekammer Rheinland-Pfalz," a German federal medical association. Patients were recruited consecutively at an oncological inpatient rehabilitation center, the "Rehabilitationsklinik Nahetal," Bad Kreuznach, Germany, between March and September 2003. They were asked to attend a group session during their first week of stay. In this session, after a complete description of the study had been presented, written informed consent was obtained from those willing to take part. Of 247 patients approached, $167(68 \%)$ consented to participate and completed questionnaires. Of those, 11 (7\%) were excluded due to limited data quality (missing values $>10 \%$ in scale items). The final study sample therefore consisted of 156 patients.

Participants' mean age was 56 years $(S D=11$, range $=31-83), 68 \%$ were married, and $74 \%$ lived together with a partner; for $54 \%$ the highest level of education was equivalent to junior high school. The time since diagnosis ranged from 1 month to 36 months with a mean post-diagnosis of 11 months $(S D=7)$. Diagnoses comprised Stage 0 (in situ carcinoma, 5\%), Stage I (31\%), Stage II (47\%), Stage III (7\%), and Stage IV (3\%) breast cancer; in 7\% information regarding stage was unavailable. Nearly all participants had received surgical treatment (65\% breast conservation, 31\% mastectomy, $1 \%$ both). In terms of religious affiliation, $49 \%$ of the women were Catholics, $35 \%$ Protestants, and 5\% members of other Christian churches; $10 \%$ had abandoned church membership, and $1 \%$ had never belonged to any denomination. These frequencies roughly correspond to the denominational distribution in the former West German states: Catholics and Protestants each comprise around $40 \%$ of the population, and other affiliation and no membership each constitute approximately 10\% (Terwey, 2003).

\section{Measures}

\section{Religious Coping}

Validated instruments for a refined assessment of religious coping are not yet available in the German language. Therefore, quite analogous to the ideas of the Brief RCOPE (Pargament et al., 1998, 2000), we developed 16 items for use with cancer patients that would fit the religious-cultural context in Germany. In contrast to the Brief RCOPE, we avoided strong religious words like "devil" or "sin." Participants rated the items on a 5-point scale from 0 ("not at all") to 4 ("very much"). An exploratory factor analysis (principal axis factoring, Varimax rotation) clearly indicated the presence of two factors (variance accounted for $=41.7$ and $26.6 \%$, respectively). The first scale, Positive Religious Coping (PRC), contained 8 items and measured the degree to which religiousness offers cancer-specific support, meaning, and solace in response to cancer (Cronbach's alpha $=0.97$; e.g., "I'm finding solace and hope in my religious faith"). The second scale, Negative Religious Coping (NRC), comprised 8 items addressing bargaining and quarreling with God, feelings of being punished by God, and religious doubt as cancer-specific responses (Cronbach's alpha $=0.89$; e.g., "I'm asking myself why God scrutinized me"). PRC and NRC were somewhat related, but not significantly, $r(156)=0.12, p=0.136$.

\section{Nonreligious Coping}

We utilized two subscales from the short version of the Freiburg Questionnaire of Coping with Illness (FKV-LIS [FQCI]; Muthny, 1989). The FQCI is a well-validated coping measure widely used in Germany. The items take the form of short statements of coping behaviors set out on a 5-point rating scale from 0 ("not at all") to 4 ("very much"). The two subscales employed are known to show the strongest connections to psychosocial adjustment and other outcome measures (Muthny, 1989) and constitute the basic dimensions of the FQCI (Hardt et al., 2003): Depressive Coping (FQCI-Dep, 5 items, e.g., "Brooding") and Active Problem-focused Coping (FQCI-Act, 5 items, e.g., "Deciding to fight against the illness"). As reported in the manual, Cronbach's alphas showed somewhat lower but acceptable values ( 0.73 for FQCI-Dep and 0.65 for FQCI-Act). Also consistent with the manual, FQCIDep and FQCI-Act were unrelated, $r(156)=0.07$, $p=0.418$.

\section{Psychosocial Adjustment}

Psychosocial adjustment was assessed with the German version of the Hospital Anxiety and Depression Scale (HADS-D; Herrmann et al., 1995), which contains two subscales (7 items each): Anxiety 
and Depression. All items are scored on a 4-point scale ranging from 0 to 3 . The HADS-D is well validated and internationally comparable (Herrmann, 1997). Cronbach's alphas in the present study, 0.79 for Anxiety (HADS-D-A) and 0.82 for Depression (HADS-D-D), are perfectly in line with prior findings. As expected, HADS-D-A and HADS-D-D were strongly correlated, $r(156)=0.66, p<0.001$.

\section{Data Analysis}

For the 156 patients included in the study, a maximum of $3(1.9 \%)$ missing values in the items of the scales was observed. Prior to the main data analyses these missing values were imputed by the expectation-maximization (EM) algorithm. The EM algorithm estimates missing data using an iterative maximum-likelihood procedure. It is one of the recommended methods for preventing biases caused by not completely random missing data processes (Allison, 2001; Schafer and Graham, 2002). The imputation was performed with the software NORM (Graham et al., 2003).

After determining descriptive statistics for the scales, research question 1 was addressed applying univariate analyses (correlation, ANOVA) as well as multiple regression analysis. To answer the question which patients tend to use which religious coping pattern religious coping scales were related to various demographic and cancer-related predictors. SPSS 12.0 for Windows software (SPSS Inc., Chicago, IL) was used for these computations.

In order to estimate the multivariate dependencies addressed in research question 2 (mediating role of nonreligious coping) and research question 3 (relative predictive power of positive and negative religious coping), structural equation modeling (SEM) was employed (Bollen, 1989; Kline, 2005). The maximum-likelihood estimation procedure (Hoogland and Boomsma, 1998; Kline, 2005) implemented in the software AMOS 5.0 (Arbuckle and Wothke, 1999) was used to develop and test all structural models. The input for SEM is the empirical covariance matrix. The covariance matrix analyzed here can be directly derived from the correlation matrix shown in the appendix.

SEM is a multivariate technique combining the properties of factor analysis, regression analysis, and path analysis, consequently enabling the definition and estimation of complex model structures. SEM thus has the potential to account for multiple influences, which may simultaneously affect various out- come variables. Furthermore, if multiple valid indicators exist, theoretically derived constructs can be modeled as so-called latent or structural variables which possess desirable psychometric properties: Since measurement error is explicitly separated from true variance within the estimation process, latent variables, unlike observed manifest indicators, do not suffer from systematic restrictions in measurement quality, given that certain criteria are met (Hair et al., 2004).

In accordance with Kline (2005), a two-step SEM procedure was applied. In the first step, a confirmatory factor analysis (CFA) was conducted to determine whether the intended constructs were indeed measured. CFA assumes each manifest variable to be a distinct indicator of an underlying latent construct, whereby different constructs are permitted to correlate with each other. The appropriateness of a specific CFA model was assessed by measures of global and local model fit.

Measures of global fit indicate whether the empirical associations among the manifest variables are appropriately reproduced by the model (Boomsma, 2000; Kline, 2005). For a variety of these global fit measures certain criteria have to be met in order to accept the model under study as plausible and parsimonious. Measures of absolute fit like the goodness of fit index (GFI) and the adjusted goodness of fit index (AGFI) reflect the discrepancy between the empirical and model implied covariance matrices. Values $\geq 0.90$ indicate an acceptable fit. The root mean square error of approximation (RMSEA) can be interpreted as the amount of information within the empirical covariance matrix that cannot be explained by the proposed model. The model may be classified as acceptable if only $8 \%$ or less of the information are not accounted for by the model (RMSEA $\leq$ 0.08 ). Furthermore, measures of incremental fit were employed (Tabachnik and Fidell, 1996): the normed fit index (NFI), the Tucker-Lewis index (TLI), and the comparative fit index (CFI). The rationale of all these three measures is that more complex, i.e., less restrictive models are penalized by a downward adjustment, while more parsimonious, i.e., more restrictive models are rewarded by an increase in the fit index. According to Bentler (1990), the CFI explicitly avoids the underestimation of fit often noted for the NFI in relatively small samples. A rule of thumb for incremental fit measures is that values $\geq 0.95$ are indicative of good fit relative to the independence model, while values $\geq 0.90$ may be interpreted as an acceptable fit. 
Measures of local fit evaluate whether each construct can be reliably estimated from its indicators (Bagozzi and Baumgartner, 1994; Hair et al., 2004) and whether the constructs within the model are sufficiently distinguishable (Fornell and Larcker, 1981). Because coefficient alpha wrongly assumes that all indicators contribute to reliability equally (Bollen, 1989) we chose composite reliability, which draws on the unstandardized regression weights and measurement error components for each indicator (Baumgartner and Homburg, 1996; Fornell and Larcker, 1981).

In the second step, a path model, as implied by research questions 2 and 3 , was specified and evaluated using measures of global fit. The significance of the relationships between the exogenous and endogenous latent variables, as well as the amount of variance explained in the endogenous variables were examined. In order to then directly answer research questions 2 and 3, specific constraints were imposed upon this model (or a reformulation of it) and tested through hierarchical model comparisons. Only if the constraints led to a significant decrease in data fit ( $\Delta \chi^{2}$ test; Homburg and Giering, 2001) the corresponding model components were considered important.

\section{RESULTS}

\section{Descriptive Statistics}

Descriptive statistics for all six scales are shown in Table I. Participants reported relatively high reliance on positive religious coping, but made only limited use of negative religious coping strategies. In terms of nonreligious coping patients most fre-

Table I. Descriptive Statistics for Scales $(N=156)$

\begin{tabular}{lcccc}
\hline Scale & $\begin{array}{c}\text { Theoretical } \\
\text { range }\end{array}$ & $M$ & $S D$ & Skewness \\
\hline PRC & $0-4$ & 1.95 & 1.31 & -0.07 \\
NRC & $0-4$ & 0.88 & 0.83 & $1.02^{* * *}$ \\
FQCI-Dep & $0-4$ & 0.94 & 0.67 & $0.83^{* * *}$ \\
FQCI-Act & $0-4$ & 2.81 & 0.72 & $-0.49^{*}$ \\
HADS-D-A & $0-3$ & 1.05 & 0.52 & 0.27 \\
HADS-D-D & $0-3$ & 0.54 & 0.47 & $1.48^{* * *}$ \\
\hline
\end{tabular}

Note. PRC: Positive Religious Coping, NRC: Negative Religious Coping, FQCI-Dep: Depressive Coping, FQCI-Act: Active Problem-focused Coping, HADS-D-A: Anxiety, HADS$\mathrm{D}-\mathrm{D}=$ Depression.

${ }^{*} p<0.05$.

${ }^{* * *} p<0.001$. quently used active problem-focused coping. In contrast, the mean score for depressive coping was comparatively low. Patients' anxiety and depression scores fell below the midpoint of the theoretical range. However, comparison with a German sample of healthy women revealed percentiles of approximately 70 for both patients' average anxiety and depression score (Herrmann et al., 1995). Participants thus experienced fairly high levels of psychosocial distress.

\section{Research Question 1: Regression of Religious Coping on Demographic and Cancer-Related Variables}

In order to determine which patients tend to use which religious coping style, positive and negative religious coping were related to various demographic variables (age, education, partner, religious affiliation) and cancer-related descriptors (time since diagnosis, surgical procedure, tumor stage). These univariate analyses (correlation, ANOVA) only indicated more negative religious coping for older women $[r(156)=0.24, p=0.003]$, least-educated patients $[F(2,143)=5.63, p=0.004$, post hoc Scheffé $]$, and partner-less women $[t(154)=2.28, p=0.024]$ as well as both less positive religious coping $[F(3,152)=8.82, p<0.001]$ and less negative religious coping $[F(3,152)=5.03, p<0.002]$ for religious nones (post hoc Scheffé).

To account for multiple dependencies between the seven demographic and cancer-related predictors, multiple regression analysis was conducted. Categorical predictors were coded as follows: education: low (0; equivalent to junior high school and lower) versus high (1; equivalent to high school and higher); partner: living without (0) versus living with (1) a partner; Catholic affiliation: Catholic (1) versus other (0); Protestant affiliation: Protestant (1) versus other (0); surgical procedure: breast conservation (0) versus mastectomy or both (1); tumor stage: less advanced (0; Stages 0 to II) versus more advanced (1; Stages III and IV).

As can be seen in Table II, negative religious coping was significantly predicted by age and partner (beta $=|0.19|$ to $|0.21|$, overall $R^{2}=0.21$ ). That is, correlations to other predictors taken into account, older and partnerless women showed more negative religious coping. No such tendencies were found for positive religious coping. Education and religious affiliation variables failed to reach significance in multiple regression analysis. As in the univariate 
Table II. Multiple Regression Summary for Regressions of Positive and Negative Religious Coping on Demographic and Cancer-Related Variables $(N=124)$

\begin{tabular}{lcc}
\hline & PRC & NRC \\
\hline Demographic variables & & \\
$\quad$ Age & 0.13 & $0.21^{*}$ \\
Education (0-1) & 0.19 & -0.14 \\
Partner (0-1) & -0.06 & $-0.19^{*}$ \\
Catholic (0-1) & 0.25 & 0.11 \\
$\quad$ Protestant (0-1) & 0.16 & 0.23 \\
Cancer-related variables & & \\
$\quad$ Time since diagnosis & -0.05 & -0.15 \\
$\quad$ Surgical procedure (0-1) & -0.01 & 0.05 \\
$\quad$ Tumor stage (0-1) & 0.01 & -0.13 \\
$R^{2}$ & 0.10 & 0.21 \\
$F(8,115)$ & 1.54 & $3.80^{* * *}$ \\
\hline Note. See text for dichotomizing (0-1) categorical predictors. \\
Standardized beta coefficients are shown. PRC: Positive Reli- \\
gious Coping, NRC: Negative Religious Coping. \\
${ }^{*} p<0.05$. \\
${ }_{*}^{* * *} p<0.001$.
\end{tabular}

approach, cancer-related variables (i.e., time since diagnosis, surgical procedure, and tumor stage) were not significantly related to either negative or positive religious coping.

\section{Structural Equation Modeling}

\section{Confirmatory Factor Analysis}

Initially, all 40 scale items were included as respective indicators of the underlying six latent constructs (i.e., "Positive Religious Coping," "Negative Religious Coping," "Depressive Coping," "Active Problem-focused Coping," "Anxiety," and "Depression"). However, according to global-fit measures, this "original CFA model" showed only poor agreement with the empirical data (see Table III, row 4): The $\chi^{2}$ value revealed significant differences between model-implied and empirical covariances. Furthermore, the fit indices GFI and AGFI as well as the incremental fit measures NFI, TLI, and CFI fell substantially below the critical threshold of 0.90 . Hence, indicators with insufficient model compatibility were sequentially eliminated from the model until criteria for a good model-fit were reached. Items were eliminated if (1) indicator reliabilities were low $(<0.3$; Hair et al., 2004) or (2) modification indices suggested that residual correlations would entail a substantial improvement of fit (Kline, 2005).

The resulting "modified CFA model" comprised 20 items and exhibited a very good global data fit (see Table III, row 5). Furthermore, indices of local fit proved that each latent construct was reliably measured by its indicators: For each manifest item, more than $30 \%$ of its information was predicted by its underlying construct (indicator reliability $>0.3$; see Table IV, column 3) and all factor loadings were significant (see Table IV, column 4). The factor reliabilities (see Table IV, column 5) as well as the average proportions of indicator variance extracted by the corresponding latent construct (see Table IV, column 6) exceeded the critical values. Only for "Anxiety" was a marginal violation observed. Finally, it was tested whether each latent variable provided information not covered by the most strongly correlated alternative construct. Significant $\Delta \chi^{2}$ tests indicated discriminant validities (see Table IV, column 7). That is to say, all latent variables could be considered sufficiently distinguishable from each other (Fornell and Larcker, 1981).

Although the measurement models were modified in order to achieve an appropriate model fit, the central properties of the structural model remained virtually identical after modification: In both the "original" and the "modified CFA model" the same structural path coefficients were significant and a similar amount of variance was explained in the endogenous constructs ("Anxiety": $62 \%$ vs. $56 \%$, "Depression": $71 \%$ vs. $71 \%$ ). This indicates that modifications did not lead to changes in the meaning of constructs.

\section{Research Question 2: Estimating Direct and Indirect Effects of Religious Coping on Psychosocial Adjustment}

After having ensured a high measurement quality of the "modified CFA model," structural relationships between latent variables were specified, as implied by research questions 2 and 3. This "full path model" (see Table III, row 7) yielded virtually the same measures of global fit as the "modified CFA model," demonstrating that the model structure was in accordance with the empirical data. Figure 1 illustrates the structural model of the "full path model," indicating estimated path coefficients and the percentage of explained variance for the endogenous structural variables. Measurement models were equivalent to those proved in the "modified CFA model" (see Table IV) and are not shown in Fig. 1. 
Table III. Measures of Global Fit for All Models Estimated and Hierarchical Model Tests $\left(\Delta \chi^{2}\right)$

\begin{tabular}{|c|c|c|c|c|c|c|c|c|c|c|}
\hline & $\chi^{2}$ & $d f$ & $p$ & $\chi^{2} / d f$ & GFI & AGFI & NFI & TLI & CFI & RMSEA \\
\hline Thresholds for acceptable fit & & & $>0.05$ & $<2$ & $\geq 0.90$ & $\geq 0.90$ & $\geq 0.90$ & $\geq 0.90$ & $\geq 0.90$ & $\leq 0.08$ \\
\hline \multicolumn{11}{|l|}{ Confirmatory factor analyses } \\
\hline Original CFA model & 1220.1 & 725 & $<0.001$ & 1.68 & 0.74 & 0.70 & 0.72 & 0.85 & 0.86 & 0.07 \\
\hline Modified CFA model & 176.1 & 155 & 0.115 & 1.14 & 0.90 & 0.87 & 0.91 & 0.98 & 0.99 & 0.03 \\
\hline \multicolumn{11}{|l|}{ Research question 2} \\
\hline Full path model & 176.2 & 156 & 0.128 & 1.13 & 0.90 & 0.87 & 0.91 & 0.98 & 0.99 & 0.03 \\
\hline Restriction & 179.6 & 160 & 0.138 & 1.12 & 0.90 & 0.87 & 0.90 & 0.98 & 0.99 & 0.03 \\
\hline$\Delta \chi^{2}$ test & 3.4 & 1 & 0.504 & & & & & & & \\
\hline \multicolumn{11}{|l|}{ Research question 3} \\
\hline Reformulated path model & 90.2 & 84 & 0.303 & 1.07 & 0.93 & 0.90 & 0.94 & 1.00 & 1.00 & 0.02 \\
\hline Restriction 1 & 90.2 & 85 & 0.329 & 1.06 & 0.93 & 0.90 & 0.94 & 1.00 & 1.00 & 0.02 \\
\hline$\Delta \chi^{2}$ test & 0.0 & 1 & 0.980 & & & & & & & \\
\hline Restriction 2 & 90.5 & 85 & 0.321 & 1.07 & 0.93 & 0.90 & 0.94 & 1.00 & 1.00 & 0.02 \\
\hline$\Delta \chi^{2}$ test & 0.3 & 1 & 0.586 & & & & & & & \\
\hline
\end{tabular}

Note. GFI: goodness of fit index, AGFI: adjusted goodness of fit index, NFI: normed fit index, TLI: Tucker-Lewis index, CFI: comparative fit index, RMSEA: root mean square error of approximation.

Information within the "full path model" can be described as follows: The latent endogenous variables "Positive" and "Negative Religious Coping" were positively correlated $(\varphi=0.18$, C.R. $=2.10$, $p=0.036)$. Both "Positive Religious Coping" $(\beta=-0.29$, C.R. $=-2.95, p=0.003)$ and "Negative
Religious Coping" $(\beta=0.29$, C.R. $=2.99, p=0.003)$ significantly affected "Depressive Coping," but not "Active Problem-focused Coping." Furthermore, "Depressive Coping" had a very strong impact on "Anxiety" $(\beta=0.67$, C.R. $=-2.95, p<0.001)$ and "Depression" $(\beta=0.79$, C.R. $=5.83, p<0.001)$. All

Table IV. Measures of Local Fit for the "Modified CFA Model"

\begin{tabular}{|c|c|c|c|c|c|c|}
\hline Factor & Item & $\begin{array}{l}\text { Indicator } \\
\text { reliability }\end{array}$ & $\begin{array}{l}t \text {-value of factor } \\
\text { loading }\end{array}$ & $\begin{array}{l}\text { Factor } \\
\text { reliability }\end{array}$ & $\begin{array}{l}\text { Average } \\
\text { variance } \\
\text { extracted }\end{array}$ & $\Delta \chi^{2}(d f=1)$ \\
\hline Thresholds for acceptable fit & & $\geq 0.3$ & & $\geq 0.6$ & $\geq 0.5$ & $p<0.05$ \\
\hline Positive & prc1 & 0.74 & $-{ }^{\mathrm{a}}$ & 0.95 & 0.80 & $32.39^{* * *}$ \\
\hline Religious & prc2 & 0.91 & $18.02^{* * *}$ & & & \\
\hline \multirow[t]{3}{*}{ Coping } & prc3 & 0.78 & $15.33^{* * *}$ & & & \\
\hline & prc4 & 0.77 & $15.10^{* * * *}$ & & & \\
\hline & prc5 & 0.83 & $16.36^{* * * *}$ & & & \\
\hline Negative & nrc1 & 0.89 & $-^{\mathrm{a}}$ & 0.86 & 0.63 & $32.39^{* * *}$ \\
\hline Religious & nrc2 & 0.76 & $15.01^{* * * *}$ & & & \\
\hline \multirow[t]{2}{*}{ Coping } & nrc3 & 0.53 & $11.14^{* * *}$ & & & \\
\hline & nrc4 & 0.31 & $7.56^{* * *}$ & & & \\
\hline \multirow[t]{3}{*}{ Depressive coping } & dc1 & 0.56 & $-^{\mathrm{a}}$ & 0.77 & 0.54 & $10.99^{* * *}$ \\
\hline & $\mathrm{dc} 2$ & 0.38 & $6.57^{* * *}$ & & & \\
\hline & dc3 & 0.35 & $6.30^{* * *}$ & & & \\
\hline \multirow[t]{2}{*}{ Active Problem-focused Coping } & ac1 & 0.48 & $-^{\mathrm{a}}$ & 0.70 & 0.55 & $90.10^{* * *}$ \\
\hline & ac2 & 0.60 & $0.66^{* *}$ & & & \\
\hline \multirow[t]{3}{*}{ Anxiety } & anx1 & 0.43 & $-{ }^{\mathrm{a}}$ & 0.73 & 0.47 & $35.02^{* * *}$ \\
\hline & anx2 & 0.37 & $6.43^{* * *}$ & & & \\
\hline & anx3 & 0.70 & $7.86^{* * *}$ & & & \\
\hline \multirow[t]{3}{*}{ Depression } & dep1 & 0.53 & $-^{\mathrm{a}}$ & 0.74 & 0.50 & $10.99^{* * *}$ \\
\hline & dep2 & 0.41 & $7.12^{* * *}$ & & & \\
\hline & dep3 & 0.49 & $7.77^{* * *}$ & & & \\
\hline
\end{tabular}

Note. For thresholds of acceptable fit see Bagozzi and Baumgartner (1994), Hair et al. (2004).

${ }^{a}$ Unstandardized values were set to equal 1 in order to ensure identifiability.

** $p<0.01$.

${ }^{* * *} p<0.001$ 


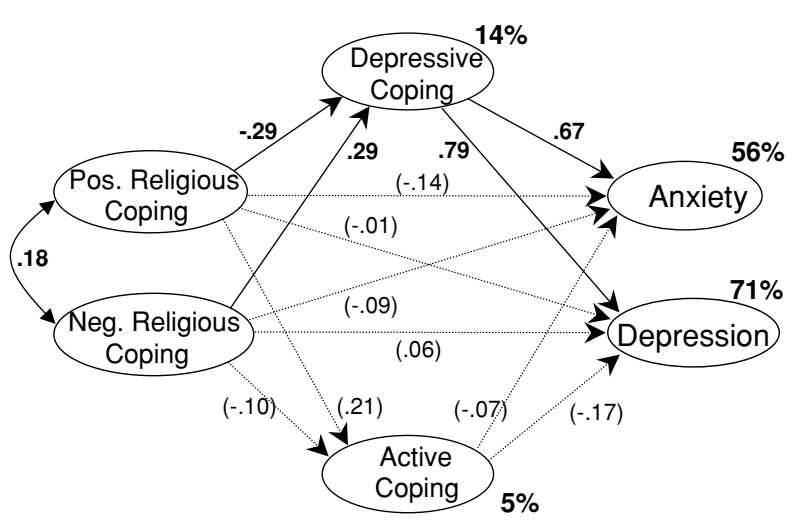

Fig. 1. "Full path model": estimated standardized path coefficients and percentage of explained variance for the endogenous structural constructs (non-significant paths appear dotted; total effects: "Positive Religious Coping" $\rightarrow$ "Anxiety" $=-0.27$, "Positive Religious Coping" $\rightarrow$ "Depression" $=-0.35$, "Negative Religious Coping" $\rightarrow$ "Anxiety" $=0.31$, "Negative Religious Coping" $\rightarrow$ "Anxiety" = 0.31; correlation of endogenous error terms of "Anxiety" and "Depression": $\psi=0.57$, C.R. $=2.52$, $p=0.012$ ).

path coefficients from "Positive" and "Negative Religious Coping" to the constructs representing psychosocial adjustment yielded non-significant values $\beta$ "PRC" $\rightarrow$ "Anxiety" $=-0.14, \quad$ C.R. $=-1.55$, $p=0.122 ; \quad \beta$ “PRC" $\rightarrow$ "Depression" $=-0.01, \quad$ C.R. $=$ $-0.06, p=0.955 ; \quad \beta$ "NRC" $\rightarrow$ "Anxiety" $=0.09$, C.R. $=$ $1.03, p=0.305 ; \quad \beta$ "NRC" $\rightarrow$ "Depression" $=0.06, \quad$ C.R. $=$ $0.65, p=0.514)$. In sum, $56 \%$ of the variance of "Anxiety" and $71 \%$ of the variance of "Depression" was explained by religious and nonreligious coping. Religious coping accounts for $14 \%$ of the variance of "Depressive Coping," but for only $5 \%$ of the variance of "Active Problem-focused Coping."

Referring to research question 2, this pattern strongly suggests that the predictive information of religious coping for psychosocial adjustment was completely mediated by nonreligious coping (especially by depressive coping). In order to explicitly test this, a hierarchical model comparison was conducted. To this end, all four direct paths from "Positive" and "Negative Religious Coping" to "Anxiety" and "Depression" were simultaneously constrained to 0 . This restriction yielded a global model fit (see Table III, row 8 , restriction) that was not significantly weaker than the fit of the "full path model" (see Table III, row 9). Thus, all direct paths from religious coping to psychosocial adjustment could be eliminated from the structural model without any loss of systematic information.
Research Question 3: Comparing the Predictive Power of Positive and Negative Religious Coping

In order to address research question 3 , the "full path model" had to be reformulated. The reformulation should allow a direct estimation of the total predictive power of religious coping on psychosocial adjustment. To this end, constructs representing nonreligious coping were eliminated. Explicitly, only direct paths from the exogenous constructs representing religious coping to the endogenous constructs "Anxiety" and "Depression" remained in the "reformulated path model." Indirect effects mediated by nonreligious coping were consequently implicitly modeled within the direct paths between exogenous and endogenous variables.

Again, the "reformulated path model" showed an excellent global model fit (see Table III, row 11). All path coefficients were significant and of medium size: $\beta$ "PRC" $\rightarrow$ "Anxiety" $=-0.35$, C.R. $=-3.61, p<$ $0.001 ; \quad \beta$ "PRC" $\rightarrow$ "Depression" $=-0.28$, C.R. $=-2.94$, $p=0.003 ; \beta$ "NRC" $\rightarrow$ "Anxiety" $=0.28, \quad$ C.R. $=3.11$, $p=0.003 ; \beta$ "NRC" $\rightarrow$ "Depression" = 0.30, C.R. $=3.14$, $p=0.002$. The question whether "Positive" and "Negative Religious Coping" had identical predictive power on "Anxiety," was tested by constraining the corresponding unstandardized regression weights in such a way as to obtain equal values (Bollen, 1989), $\mid b$ "PRC" $\rightarrow$ "Anxiety" $\mid=b$ “NRC" $\rightarrow$ "Anxiety." This restriction yielded a global model fit (see Table III, row 12 , restriction 1) that was not significantly weakened in comparison with the fit of the "reformulated path model." As to "Depression," the restriction $\mid b$ “PRC" $\rightarrow$ "Depression" $\mid=b$ "NRC" $\rightarrow$ "Depression" (see Table III, row 14, restriction 2) also led to a nonsignificant decrease in model fit (see Table III, row 15). Thus, we can conclude that both religious coping constructs affected psychosocial adjustment to the same extent.

\section{DISCUSSION}

The present cross-sectional study investigated the role of religious coping in a sample of 156 German breast cancer patients. Previous psychooncological research concerning religious resources has predominantly dealt with general religiousness or beneficial religious coping (Stefanek et al., 2005; Thuné-Boyle et al., 2006). Only recently, Sherman et al. (2005) systematically explored both positive and negative components of religious coping. The 
current study takes a comparable approach. In following Pargament et al. (1998), religious coping was broken down into two broad patterns: positive religious coping, i.e., the constructive search for support, meaning, and solace in religion, and negative religious coping, i.e., religious struggle and doubt. Descriptive statistics for scales indicated, in accordance to the findings by Sherman et al. (2005), that participants predominantly relied on positive religious coping and used negative religious coping only to a limited degree (see Table I).

The specific purpose of the present study was threefold: (1) The first research question was whether patients with certain demographic and cancer-related characteristics tended to prefer a particular religious coping pattern. The following two research questions were addressed using structural equation modeling, thereby promoting the use of this methodologically advantageous approach to religious coping research: (2) It was examined whether positive and negative religious coping contributed to the prediction of psychosocial adjustment independently of two basic nonreligious coping styles, i.e., depressive coping and active problem-focused coping. (3) Furthermore, the relative predictive power of positive and negative religious coping on psychosocial adjustment was explored.

According to the multiple regression analysis carried out in research question 1 (see Table II), positive religious coping could not be predicted by various demographic and cancer-related variables. In contrast, negative religious coping was found to be more frequently reported by older women and patients living without a partner; beta coefficients were of low to moderate size (beta $=|0.19|$ to $|0.21|)$. One possible explanation is that older women may generally been subjected to a more negative religious socialization. Being raised with the image of a vengeful God, this may be especially actualized in particularly lonesome and traumatic times. Religious affiliation as well as cancer-related characteristics did not show up as significant predictors of religious coping.

As to research question 2, the SEM "full path model" did not indicate significant direct paths between religious coping and psychosocial adjustment. Figure 1 illustrates that nonreligious coping strategies (especially "Depressive Coping") seemed to play a prominent mediating role between religious coping and outcomes. In fact, when the direct paths from religious coping to outcomes were dropped, there was no significant loss of fit in the structural model (see Table III). Hence, it is plausible to as- sume that religious coping was totally mediated by nonreligious coping strategies; positive and negative religious coping contributed only indirectly to psychosocial adjustment. Thus, our SEM results in German breast cancer patients do not support the conclusion by Burker et al. (2005), Pargament et al. (1990; Pargament, 2002), and Tix and Frazier (1998) that religious coping variables contribute to the prediction of outcomes beyond the effects of nonreligious coping strategies. However, it has to be noted that this reasoning was based on investigations in samples other than cancer patients. Studies based on cancer patients have so far not revealed a clear picture. Our result seems to be somewhat similar to the finding of Nairn and Merluzzi (2003) that nonreligious self-efficacy was, at least partially, a mediating variable between religious coping and adjustment in a mixed sample of cancer patients. However, it may well be possible that our mediation pattern is to some extent explained by the less important role of religion in Germany, thus reflecting religious-cultural specifics.

Some other aspects of the "full path model" depicted in Fig. 1 are noteworthy: First, only "Depressive Coping" but not "Active Problem-focused Coping" was a mediating variable. The paths between religious coping constructs and "Active Problemfocused Coping" as well as those between "Active Problem-focused Coping" and outcome variables failed to reach significance. Our results therefore do not replicate the consistent finding of the three equivalent studies conducted by Holland et al. (1999) in the United States, Baider et al. (1999) in Israel, and Mehnert et al. (2003) in Germany, whereby religious/spiritual variables were strongly related to this beneficial coping style. In part, this discrepancy may be due to the specific nonreligious coping measure utilized in the three foregoing studies. This measure included four items relating to religious and spiritual themes and thus may account for the high correlation (Holland et al., 1999). Furthermore, however, it also is possible that active problem-focused coping will play a more prominent mediating role if beneficial outcomes (e.g., health-related quality of life, psychological well-being, or stress-related growth) are studied as opposed to the negative outcomes (anxiety, depression) emphasized in the current investigation. Further research would help delineate which mediating patterns of nonreligious coping are prominent in which outcome domains.

Second, the latent endogenous constructs "Positive" and "Negative Religious Coping" 
were significantly positively related to each other $(\varphi=0.18)$. On the manifest level the original scales PRC and NRC were also positively associated, albeit not significantly $(r=0.12)$. The moderate positive relationship between the two religious coping patterns denotes that patients may use positive and negative religious coping simultaneously. Whilst someone may frequently engage in positive religious coping, this does not preclude religious struggle and doubt. This point was previously emphasized by Fitchett et al. (2004, p. 191): "Positive religious coping is not the opposite of negative religious coping."

Finally, whereas "Depressive Coping" was negatively related to "Positive Religious Coping" and positively to "Negative Religious Coping," it can be seen from Fig. 1 that $\beta$ "PRC" $\rightarrow$ "Depressive Coping" had the same magnitude as $\beta$ "NRC" $\rightarrow$ "Depressive Coping" $(|\beta|=0.29)$. This already suggests that "Positive" and "Negative Religious Coping" were equally predictive of psychosocial adjustment. In order to explicitly test this, thereby addressing research question 3, the "full path model" was reformulated and restricted in such a way that the direct paths between both religious coping patterns on the one hand and "Anxiety" and "Depression," respectively, on the other hand were of equal size. In fact, these constraints did not lead to a significant loss of fit in the structural model (see Table III) so that the predictive power on psychosocial adjustment in the present study was virtually identical for "Positive" and "Negative Religious Coping." Thus, our data do not confirm the recent finding by Sherman et al. (2005), whereby only negative but not positive religious coping had predictive power on psychosocial outcomes in multiple myeloma patients. The reasons for this discrepancy are not clear but may reflect differences in religious-cultural background, cancer type, stage of illness, or phase of treatment.

Altogether, the present findings in German breast cancer patients suggest that religious coping affects nonreligious coping strategies, especially depressive coping. In turn, depressive coping, although less frequently used in our sample (see Table I), turned out to be a strong predictor of anxiety and depression (see Fig. 1). The contributions of positive and negative religious coping to depressive coping were of the same magnitude but opposite direction: Depressive coping was predicted negatively by positive religious coping and positively by negative religious coping. Depressive coping thus proved to be in part religiously colored. In sum, religious cop- ing accounted for $14 \%$ of the variance of depressive coping in our sample.

Although religious coping appeared to be completely mediated by depressive coping in the current study, it should not be neglected in patients facing cancer. For practical reasons, appropriately addressing positive and negative religious coping may substantially reduce patients' use of depressive coping. Specifically, interventions designed to encourage benevolent religious reframing, facilitate one's finding meaning, and take struggling with faith seriously seem promising (Pargament, 1997). In inquiring patients, both positive and negative aspects of religious coping should always be explored (Sherman et al., 2005). It should be noted that positive religious coping does not preclude religious struggle and doubt. Furthermore, according to our data, older and partner-less women seem to be more prone to engage in negative religious coping. Clinical interviews could help to understand patients' religious coping patterns against the background of their religious preferences and spiritual history (e.g., Anandarajah and Hight, 2001; Frick et al., 2006; Puchalski and Romer, 2000).

\section{Limitations and Concluding Remarks}

Notable features of this investigation include evaluation of both positive and negative components of religious coping in a relatively homogeneous sample of breast cancer patients. Moreover, this study is one of the few to examine religious coping among German patients and one of the first in this realm to bring a structural equation modeling approach to data analysis. In focusing reliable latent constructs, SEM enables the description and estimation of complex relationships.

However, several limitations of the present study also deserve to be mentioned. First, our homogenous German sample limits the scope for generalizing the findings to other populations of cancer patients. The participants, newly diagnosed with breast cancer, were exclusively women and had a relatively favorable prognosis. Second, psychological adjustment in this study was regarded as absence of anxiety and depression as measured by the HADSD. Surely, this does not reflect the complexity of psychological adjustment and also limits the ability to make generalizations from the findings. Third, we did not use a measure of response bias. Although German studies do not support a systematic response 
bias in regard to religion (e.g., Zwingmann, 1991), the potential role of such a tendency cannot be ruled out. Fourth, the data and the resulting structural equation model stem from a cross-sectional sample. Therefore, the path model does not demonstrate causal relationships. Moreover, it reflects only a snapshot in time. Patients may use different religious and nonreligious coping methods and experience different states of psychosocial adjustment over the long-term (Pargament et al., 1998; Sherman et al., 2005). Only longitudinal research could help differentiate these probably more complex relationships (Stefanek et al., 2005). Fifth, in the first step of SEM several items had to be eliminated from the "original CFA model" in order to reach an excellent agreement with empirical data. Though this modification did not lead to changes in the meaning of the constructs, it was partly exploratory in nature and needs cross validation. Finally, the SEM approach applied here did not control for potential demographic and cancer-related confounders. However, after inspecting correlations, it can be assumed that these variables have only limited influences $(\max .|r|=0.24)$.

Despite the study's limitations, there appear to be sufficient grounds for arguing that religious coping may play a substantial role in the adjustment of German breast cancer patients. Findings suggest that religious coping primarily affects depressive coping, thus indirectly influencing the outcomes of the adaptation process. Our study also underscores the need for investigators and clinicians to distinguish between positive and negative forms of religious coping. Despite the less important role of religion in Germany, the results of the present study by all means correspond to previous Anglo-American research. However, some discrepancies may reflect differences in religious-cultural background. Since US-American findings are limited to their specific cultural context, they should be further augmented by contributions from European as well as from other countries. In the end, we hope that our study will stimulate further German research in the area of religion and health. 


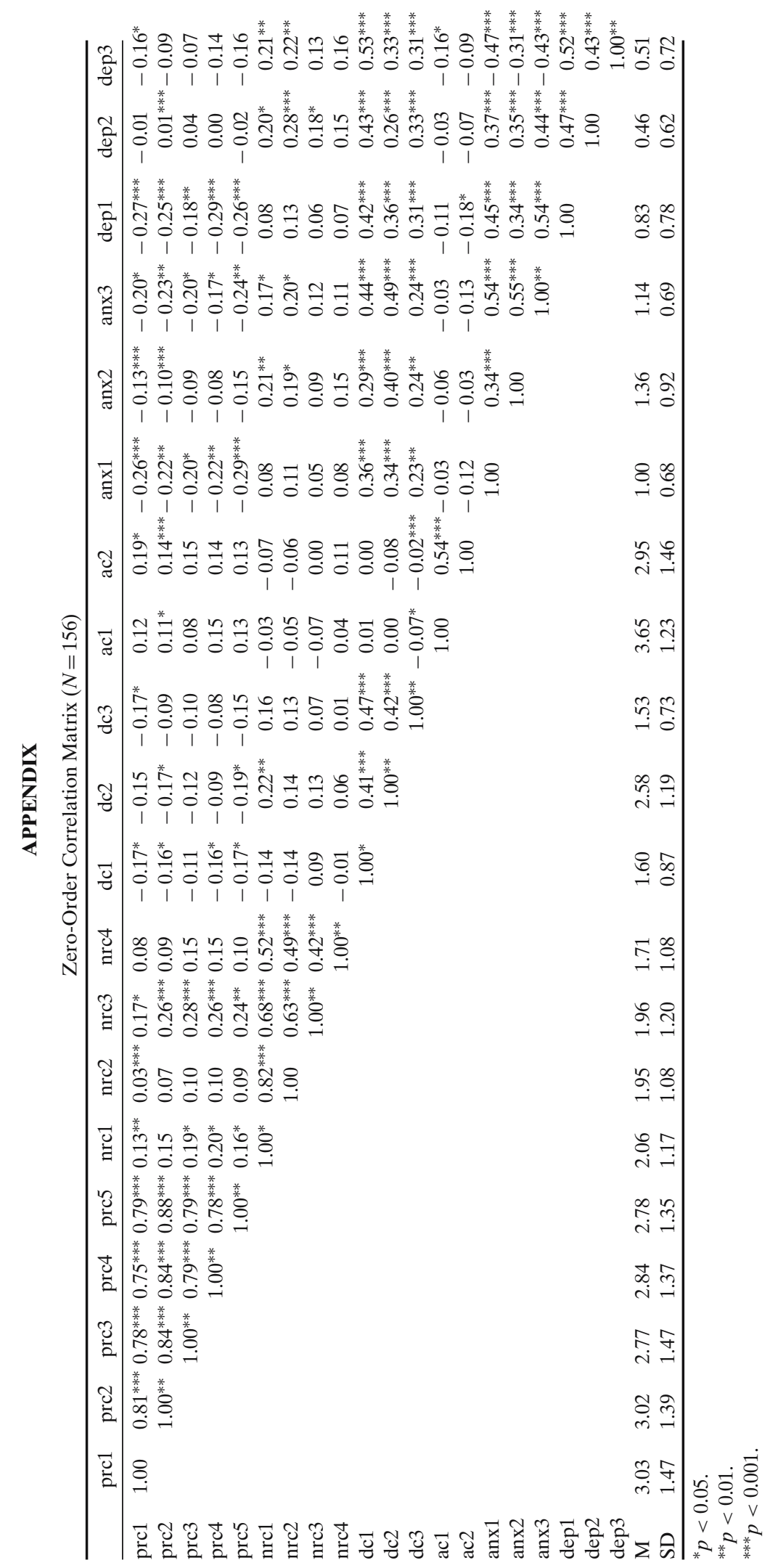




\section{ACKNOWLEDGMENTS}

This research was supported by a grant from the Volkswagen Foundation (Germany) to Sebastian Murken.

\section{REFERENCES}

Alferi, S. M., Culver, J. L., Carver, C. S., Arena, P. L., and Antoni, M. H. (1999). Religiosity, religious coping, and distress: A prospective study of Catholic and Evangelical women in treatment for early-stage breast cancer. J. Health Psychol. 4: 343-356.

Allison, P. D. (2001). Missing Data. Sage, Thousand Oaks.

Anandarajah, G., and Hight, E. (2001). Spirituality and medical practice: Using the HOPE questions as a practical tool for spiritual assessment. Am. Fam. Physician 63: 81-89.

Ano, G. G., and Vasconcelles, E. B. (2005). Religious coping and psychological adjustment to stress: A meta-analysis. J. Clin. Psychol. 61: 1-20.

Arbuckle, J. L., and Wothke, W. (1999). AMOS 4.0 User's Guide, Small-Waters Corporation, Chicago, IL.

Baumgartner, H., and Homburg, C. (1996). Applications of structural equation modeling in marketing and consumer research: A review. Int. J. Res. Mark. 13: 139-161.

Bagozzi, R., and Baumgartner, H. (1994). The evaluation of structural equation models and hypothesis testing. In Bagozzi, R. (Ed.), Principles of Marketing Research, Blackwell Publishers, Cambridge, MA, pp. 386-422

Baider, L., Russak, S. M., Perry, S., Kash, K., Gronert, M., Fox, B., Holland, J. C., and Kaplan-DeNour, A. (1999). The role of religious and spiritual beliefs in coping with malignant melanoma: An Israeli sample. Psychooncology 8: 27-35.

Bentler, P. M. (1990). Comparative fit indexes in structural models. Psychol. Bull. 107: 238-246.

Bishop, G. (1999). Poll trends. Americans' belief in God. Public Opin. Q. 63: 421-434.

Bollen, K. A. (1989). Structural Equations with Latent Variables. Wiley, New York.

Boomsma, A. (2000). Reporting analyses of covariance structures. Struct. Equation Model. 7: 461-483.

Brady, M. J., Peterman, A. H., Fitchett, G., Mo, M., and Cella, D. (1999). A case for including spirituality in quality of life measurement in oncology. Psychooncology 8: 417-428.

Burker, E. J., Evon, D. M., Sedway, J. A., and Egan, T. (2005). Religious and non-religious coping in lung transplant candidates: Does adding God to the picture tell us more? J. Behav. Med. 28: $513-526$

Büssing, A., Ostermann, T., and Matthiessen, P. F. (2005). Search for meaningful support and the meaning of illness in German cancer patients. Anticancer Res. 25: 1449-1455.

Carver, C. S., Pozo, C., Harris, S. D., Noriega, V., Scheier, M. F., Robinson, D. S., Ketcham, A. S., Moffat, F. L., Jr., and Clark, K. C. (1993). How coping mediates the effect of optimism on distress: A study of women with early stage breast cancer. $J$. Pers. Soc. Psychol. 65: 375-390.

Cotton, S. P., Levine, E. G., Fitzpatrick, C. M., Dold, K. H., and Targ, E. (1999). Exploring the relationships among spiritual well-being, quality of life, and psychological adjustment in women with breast cancer. Psychooncology 8: 429-438.

Coward, D. D. (1995). Self-transcendence: Making meaning from the cancer experience. Qual. Life 4: 53-58.

Exline, J. J., and Rose, E. (2005). Religious and spiritual struggles. In Paloutzian, R. F., and Park, C. L. (Eds.), Handbook of the
Psychology of Religion and Spirituality, Guilford, New York, pp. 315-330.

Feher, S., and Maly, R. C. (1999). Coping with breast cancer in later life: The role of religious faith. Psychooncology 8: 408416.

Ferring, D., Filipp, S.-H., and Klauer, T. (1994). Korrelate der Überlebenszeit bei Krebspatienten: Ergebnisse einer followback-Studie [Correlates of survival time in cancer patients: results of a follow-back study]. In Heim, E., and Perrez, M. (Eds.), Krankheitsverarbeitung, Hogrefe, Göttingen, pp. 6373.

Filipp, S.-H., Klauer, T., Freudenberg, E., and Ferring, D. (1990). The regulation of subjective well-being in cancer patients: An analysis of coping effectiveness. Psychol. Health 4: 305317.

Fitchett, G., Murphy, P. E., Kim, J., Gibbons, J. L., Cameron, J. R., and Davis, J. A. (2004). Religious struggle: Prevalence, correlates, and mental health risks in diabetic, congestive heart failure, and oncology patients. Int. J. Psychiatry Med. 34: 179196.

Flannelly, L. T., Flannelly, K. J., and Weaver, A. J. (2002). Religious and spiritual variables in three major oncology nursing journals: 1990-1999. Oncol. Nurs. Forum 29: 679685.

Fornell, C., and Larcker, D. F. (1981). Evaluating structural equation models with unobservable variables and measurement error. J. Marketing Res. 18: 39-50.

Frick, E., Riedner, C., Fegg, M., Hauf, S., and Borasio, G. D. (2006). A clinical interview assessing cancer patients' spiritual needs and preferences. Eur. J. Cancer Care (Engl.) 15 238-243.

Gall, T. L. (2000). Integrating religious resources within a general model of stress and coping: Long-term adjustment to breast cancer. J. Religion Health 39: 167-182.

Gall, T. L., Charbonneau, C., Clarke, N. H., Grant, K., Joseph, A., and Shouldice, L. (2005). Understanding the nature and role of spirituality in relation to coping and health: Conceptual framework. Can. Psychol. 46: 88-104.

Gioiella, M. E., Berkman, B., and Robinson, M. (1998). Spirituality and quality of life in gynecologic oncology patients. Cancer Pract. 6: 333-338.

Graham, J. W., Cumsille, P. E., and Elek-Fisk, E. (2003). Methods for handling missing data. In Schinka, J. A., and Velicer, W. F. (Eds.), Research Methods in Psychology, Wiley, New York, pp. $87-114$

Hair, J. F., Anderson, R. E., Tatham, R. L., and Black, W. C. (2004). Multivariate Data Analysis. Prentice Hall, Upper Saddle River, NJ.

Hardt, J., Petrak, F., Egle, U. T., Kappis, B., Schulz, G., and Küstner, E. (2003). Was misst der FKV? Eine Überprüfung des Freiburger Fragebogens zur Krankheitsverarbeitung bei Patienten mit unterschiedlichen Erkrankungen [What does the FQCI measure? An examination of the Freiburg Questionnaire of Coping with Illness in patients with various diseases]. Z. Klin. Psychol. Psychother. 32: 41-50.

Herrmann, C. (1997). International experiences with the Hospital Anxiety and Depression Scale-A review of validation data and clinical results. J. Psychosom. Res. 42: 17-41.

Herrmann, C., Buss, U., and Snaith, R. P. (1995). HADS-DHospital Anxiety and Depression Scale-Deutsche Version [HADS-D_German version]. Huber, Bern.

Holland, J. C., Passik, S., Kash, K. M., Russak, S. M., Gronert, M. K., Sision, A., Lederberg, M., Fox, B., and Baider, L. (1999). The role of religious and spiritual beliefs in coping with malignant melanoma. Psychooncology 8: 14-26.

Homburg, C., and Giering, A. (2001). Personal characteristics as moderators of the relationship between customer satisfaction and loyalty-An empirical analysis. Psychol. Marketing 18: $43-66$. 
Hoogland, J. J., and Boomsma, A. (1998). Robustness studies in covariance structure modeling: An overview and a metaanalysis. Sociol. Methods Res. 26: 329-367.

Jagodzinski, W., and Dobbelaere, K. (1995). Secularization and church religiosity. In van Deth, J. W., and Scarbrough, E. (Eds.), The Impact of Values, Oxford University Press, Oxford, pp. 76-119.

Kline, R. B. (2005). Principles and Practice of Structural Equation Modeling, 2nd ed. Guilford, New York.

Koenig, H. G., McCullough, M. E., and Larson, D. B. (Eds.) (2001). Handbook of Religion and Health, Oxford University Press, Oxford.

Levin, J. S. (1996). How religion influences morbidity and health: Reflections on natural history, salutogenesis and host resistence. Soc. Sci. Med. 43: 849-864.

MacLean, C. D., Susi, B., Phifer, N., Bynum, D., Franco, M., Klioze, A., Monroe, M., Garrett, J., and Cykert, S. (2003). Patient preference for physician discussion and practice of spirituality. Results from a multicenter patient survey. J. Gen. Intern. Med. 18: 38-43.

Mehnert, A., Rieß, S., and Koch, U. (2003). Die Rolle religiöser Glaubensüberzeugungen bei der Krankheitsbewältigung Maligner Melanome [The role of religious beliefs in coping with malignant melanoma]. Verhaltenstherapie und Verhaltensmedizin 24: 147-166.

Moadel, A., Morgan, C., Fatone, A., Grennan, J., Carter, J., Laruffa, G., Skummy, A., and Dutcher, J. (1999). Seeking meaning and hope: Self-reported spiritual and existential needs among an ethnically-diverse cancer patient population. Psychooncology 8: 378-385.

Muthny, F. A. (1989). Freiburger Fragebogen zur Krankheitsverarbeitung $(F K V)$. Manual [Freiburg Questionnaire of Coping with Illness (FQCI). Manual]. Beltz Test, Weinheim.

Muthny, F. A., Bechtel, M., and Spaete, M. (1992). Laienätiologien und Krankheitsverarbeitung bei schweren körperlichen Erkrankungen [Lay theories and coping with severe somatic diseases]. Psychother. Psych. Med. 42: 41-53.

Nairn, R. C., and Merluzzi, T. V. (2003). The role of religious coping in adjustment to cancer. Psychooncology 12: 428441.

Pargament, K. I. (1997). The Psychology of Religion and Coping: Theory, Research, Practice. Guilford, New York.

Pargament, K. I. (2002). Is religion nothing but. . .?: Explaining religion versus explaining religion away. Psychol. Inq. 13: 239244.

Pargament, K. I., Ano, G. G., and Wachholtz, A. B. (2005). The religious dimension of coping: Advances in theory, research, and practice. In Paloutzian, R. F., and Park, C. L. (Eds.), Handbook of the Psychology of Religion and Spirituality, Guilford, New York, pp. 479-495.

Pargament, K. I., Ensing, D. S., Falgout, K., Olsen, H., Reilly, B., Van Haitsma, K., Warren, R. (1990). God help me: (I): Religious coping efforts as predictors of the outcomes to significant negative life events. Am. J. Community Psychol. 56: 519543.

Pargament, K. I., Koenig, H. G., and Perez, L. M. (2000). The many methods of religious coping: Development and initial validation of the RCOPE. J. Clin. Psychol. 56: 519-543.

Pargament, K. I., Smith, B. W., Koenig, H. G., and Perez, L. M. (1998). Patterns of positive and negative religious coping with major life stressors. J. Sci. Study Relig. 37: 710-724.

Plante, T. G., and Sherman, A. C. (Eds.) (2001). Faith and Health Psychological Perspectives. Guilford, New York.

Puchalski, C. M., and Romer, A. L. (2000). Taking a spiritual history allows clinicians to understand patients more fully. J. Palliat. Med. 3: 129-137.
Rifkin, A., Doddi, S., Karagji, B., and Pollack, S. (1999). Religious and other predictors of psychosocial adjustment in cancer patients. Psychosomatics 40: 251-256.

Schafer, J. L., and Graham, J. W. (2002). Missing data: Our view of the state of the art. Psychol. Methods 7: 147-177.

Schnoll, R. A., Harlow, L. L., and Brower, L. (2000). Spirituality, demographic and disease factors, and adjustment to cancer. Cancer Pract. 8: 298-304.

Sherman, A. C., and Simonton, S. (2001). Assessment of religiousness and spirituality in health research. In Plante, T. G., and Sherman, A. C. (Eds.), Faith and Health: Psychological Perspectives, Guilford, New York, pp. 139-163.

Sherman, A. C., Simonton, S., Adams, D. C., Vural, E., and Hanna, E. (2000). Coping with head and neck cancer during different phases of treatment. Head Neck 22: 787-793.

Sherman, A. C., Simonton, S., Latif, U., Spohn, R., and Tricot, G. (2005). Religious struggle and religious comfort in response to illness: Health outcomes among stem cell transplant patients. J. Behav. Med. 28: 359-367.

Siegel, K., Anderman, S. J., and Schrimshaw, E. W. (2001). Religion and coping with health-related stress. Psychol. Health 16 : 631-653.

Silberfarb, P. M., Anderson, K. M., Rundle, A. C., Holland, J. C., Cooper, M. R., and McIntyre, O. R. (1991). Mood and clinical status in patients with multiple myeloma. J. Clin. Oncol. 9: 2219-2224.

Stefanek, M., McDonald, P. G., and Hess, S. A. (2005). Religion, spirituality and cancer: Current status and methodological challenges. Psychooncology 14: 450-463.

Tabachnik, B. G., and Fidell, L. S. (1996). Using Multivariate Statistics. Harper Collins, New York.

Tate, D. G., and Forchheimer, M. (2002). Quality of life, life satisfaction, and spirituality-comparing outcomes between rehabilitation and cancer patients. Am. J. Phys. Med. Rehabil. 8: 400-410.

Taylor, E. J. (1995). Whys and wherefores: Adult patient perspectives of the meaning of cancer. Semin. Oncol. Nurs. 11: 3240.

Terwey, M. (2003). Kirchen weiter auf der VerliererstraßeInferno und Aberglauben im Aufwind? [Churches disappearing furthermore-inferno and superstition coming?]. ZAInformation (52): 93-119.

Thuné-Boyle, I. C., Stygall, J. A., Keshtgar, M. R., and Newman, S. P. (2006). Do religious/spiritual coping strategies affect illness adjustment in patients with cancer? A systematic review of the literature. Soc. Sci. Med. 63: 151-164.

Tix, A. P., and Frazier, P. A. (1998). The use of religious coping during stressful life events. Main effects, moderation, and mediation. J. Consult. Clin. Psychol. 66: 411-422.

Zwingmann, C. (1991). Religiosität und Lebenszufriedenheit. Empirische Untersuchungen unter besonderer Berücksichtigung der religiösen Orientierung [Religiousness and life satisfaction. Empirical studies with special regard to religious orientation]. Roderer, Regensburg.

Zwingmann, C. (2005a). Erfassung von Spiritualität/Religiosität im Kontext der gesundheitsbezogenen Lebensqualität [Assessment of spirituality/religiosity in the context of health-related quality of life]. Psychother. Psych. Med. 55: 241-246.

Zwingmann, C. (2005b). Spiritualität/Religiosität als Komponente der gesundheitsbezogenen Lebensqualität? [Spirituality/religiosity as a component of health-related quality of life?]. Wege zum Menschen 57: 68-80.

Zwingmann, C., and Murken, S. (2000). Coping with an uncertain future: Religiosity and millenarianism. Archiv für Religionspsychologie 23: 11-28. 